\title{
Transfer of Acholeplasma bactoclasticum Robinson and Hungate to the Genus Anaeroplasma (Anaeroplasma bactoclasticum [Robinson and Hungate] comb.nov.): Emended Description of the Species
}

\author{
ISADORE M. ROBINSON AND MILTON J. ALLISON \\ National Animal Disease Center, Agricultural Research Service, U. S. Department of Agriculture, \\ Ames, Iowa 50010
}

\begin{abstract}
An anaerobic bacteriolytic mycoplasma was isolated by Robinson and Hungate and designated Acholeplasma bactoclasticum sp.n. We found that this strain and four similar isolates from the ovine rumen have a requirement for cholesterol and thus do not belong in the genus Acholeplasma. The morphological, cultural, and biochemical properties of these organisms are similar to those of a group of non-bacteriolytic anaerobic mycoplasmas that do not fit well in genera previously established for mycoplasmas and thus have been placed in a newly described genus, Anaeroplasma. We propose that the organisms isolated by Robinson and Hungate be transferred to the new genus as Anaeroplasma bactoclasticum (Robinson and Hungate) comb.nov., of which ATCC 27112 is the type strain.
\end{abstract}

Robinson and Hungate (6) isolated a strictly anaerobic, bacteriolytic microorganism from bovine rumens. Casein (skim milk) was hydrolyzed by a proteolytic extracellular enzyme. Also, various heat-killed cells, including those of Escherichia coli but not Bacillus megaterium, were lysed by an extracellular enzyme that attacked the peptidoglycan layer of the cell wall. Both of these lytic activities were sensitive to oxygen.

The microorganism was placed in the order Mycoplasmatales on the basis of colonial and microscopic morphology, ability to pass through a $0.45-\mu \mathrm{m}$ pore size membrane filter, and resistance to penicillin (9). When cultivated in the absence of inhibitors of cell wall synthesis, no reversion to walled morphology could be detected. A sterol requirement was not shown when the organism was grown in a medium containing $E$. coli cells, vitamins, volatile fatty acids, hemin, and galactose; thus, it was assigned to the family Acholeplasmataceae, genus Acholeplasma. The organism differed from previously described Acholeplasma species and was classified as a new species, Acholeplasma bactoclasticum.

We have found that the anaerobic mycoplasma strain isolated by Robinson and Hungate (6), as well as four new similar isolates, require cholesterol as well as a factor(s) in bacterial lipopolysaccharide (LPS) for growth. Therefore, we have reexamined some of the characteristics used by Robinson and Hungate
(6) in the description of Acholeplasma bactoclasticum to determine the proper taxonomic niche for this organism.

\section{MATERIALS AND METHODS}

Strain JR is our designation for the anaerobic rumen mycoplasma obtained from J. Robinson (Diss. Abstr, Int. B 32:7196, 1972). A transfer of the same strain was deposited with the American Type Culture Collection as the type strain of Acholeplasma bactoclasticum under the number ATCC 27112 (6). A number of anaerobic bactoclastic strains were isolated from sheep ruminal contents (5), and studies with four of these strains from a $10^{7}$ dilution (7LA) and a $10^{5}$ dilution (5LA, 5LB, and 5LC) are described here.

The media and procedures used were those of Robinson and Hungate (6), modified as described in detail elsewhere (5).

\section{RESULTS AND DISCUSSION}

Numbers of anaerobic mycoplasmas in the rumen. Obligately anaerobic mycoplasmas capable of hydrolyzing autoclaved $E$. coli cells were detected in ruminal contents of both cattle and sheep (5). The lytic organisms were usually present at between $10^{5}$ and $10^{7}$ viable units per gram $($ mean $=7.6 \times 10 \% \mathrm{~g}$ from nine samples from four cows and two sheep) of ruminal contents. These results are similar to culture counts of cytoclastic organisms reported by Robinson and Hungate (6). A new anaerobic mycoplasma not possessing proteolytic or bactoclastic capabilities was also detected at higher concentrations $\left(10^{7}\right.$ to $\left.10^{8} / \mathrm{g}\right)$ in ruminal con- 
tents from both sheep and cattle, and it has been described in a separate publication (5).

Colonial and cellular morphology. We could not distinguish between lytic and nonlytic organisms by colonial morphology; surface colonies of both types exhibited the "fried-egg" appearance that is characteristic of many mycoplasmas. The average diameter of surface colonies was about $1 \mathrm{~mm}$; subsurface colonies were golden, irregular, and often multilobed. These descriptions conform closely to that reported for the type strain of Acholeplasma bactoclasticum, ATCC 27112 (Robinson, Diss. Abstr. Int. B).

Cellular morphologies of the new bacteriolytic mycoplasma isolates (7LA, 5LA, 5LB, 5LC) were similar to that of Acholeplasma bactoclasticum (6). Cells of these lytic organisms are nonmotile, gram-negative, coccoid elements about $500 \mathrm{~nm}$ in diameter. Phase microscopy revealed single cells, dumbbell forms, and clusters of coccoid forms joined by short filaments. Thin sections of strain 7LA (Fig. 1) revealed cells bounded by a trilaminar membrane with no distinguishable cell wall.

Physiological and nutritional characteristics. Growth of all strains was inhibited by oxygen. Pre-reduced media maintained in an anaerobic system for exclusion of oxygen were required for growth. All strains hydrolyzed $E$. coil cells when grown in PIM (5) containing autoclaved $E$. coli cells $(5 \mathrm{mg} / \mathrm{ml})$.

All strains grew in CRFB medium (5) containing mineral salts, Trypticase, yeast extract, carbohydrates, and ruminal fluid. In another medium, MM-10 (5), which contained Trypticase, yeast extract, hemin, and a mixture of short-chain fatty acids, the requirement for ruminal fluid could be replaced by the addition of both LPS extracted by trichloroacetic acid

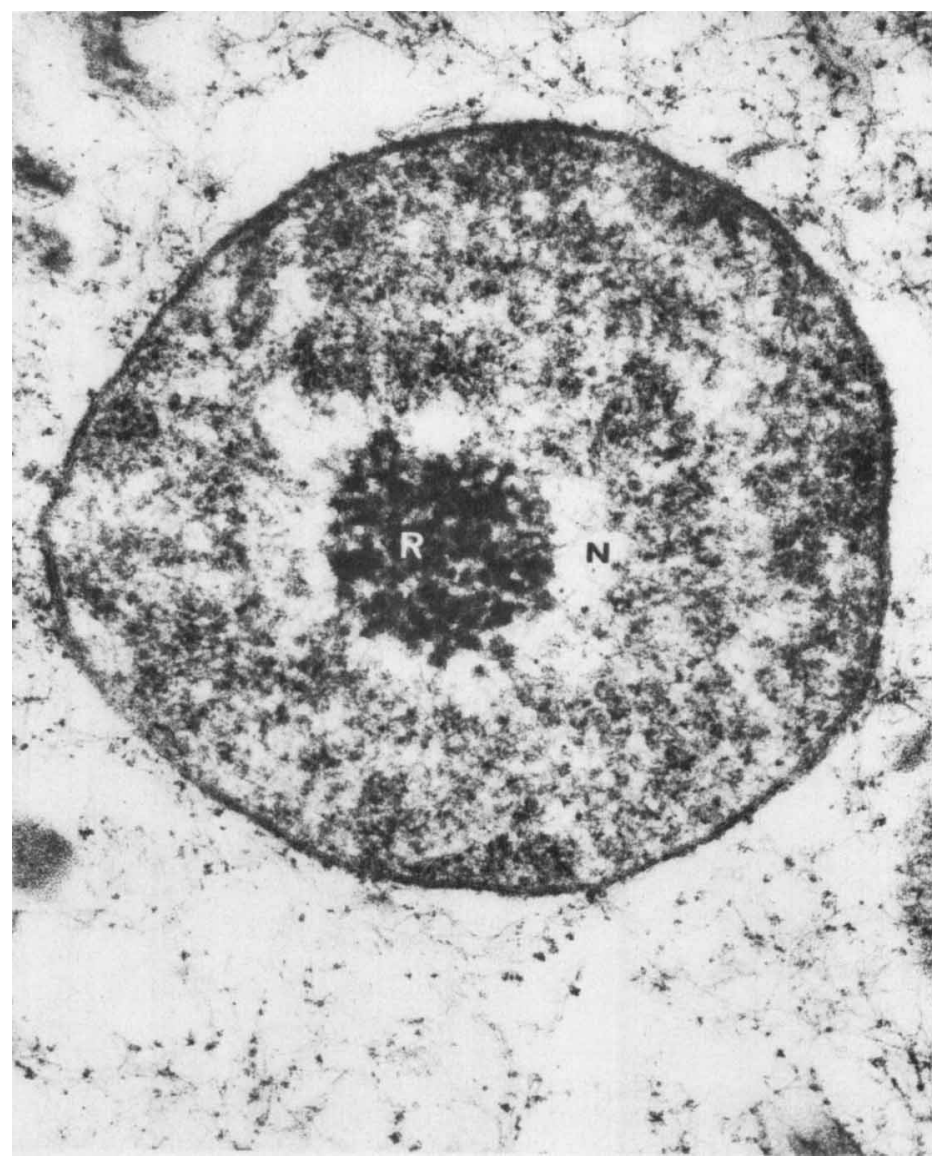

Fig. 1. Anaerobic mycoplasma (strain 7LA); 24-h-old culture. Centrally located in the cell is a less-dense region within which there are delicate strands of nuclear material $(N)$. A cluster of ribosomes $(R)$ can also be seen. $\times 120,000$. 
from $E$. coli (LPS Boivin) and by cholesterol (Table 1). Deletion of hemin from this medium did not affect growth of the two strains tested, 7LA and JR. Less growth of all strains was obtained when the mixture of volatile fatty acids was deleted.

The requirement for LPS agrees with the work of Robinson (Diss. Abstr. Int. B), who found that strain JR was stimulated when LPS prepared by phenol extraction (11) from $E$. coli was added to a medium containing $30 \%$ ruminal fluid.

Measurement of the growth responses of these organisms to LPS Boivin and cholesterol in MM-10 are given in Table 1, expt. 1 . When a $1 \%$ inoculum from CRFB medium was used, none of the mycoplasmas grew in the absence of LPS Boivin and cholesterol. All except strain JR grew without added cholesterol when LPS Boivin was added to the medium. Growth of strain $\mathrm{JR}$ was measurable only when both LPS Boivin and cholesterol were present, and growth of all the other strains was stimulated by cholesterol in the presence of LPS Boivin.

When the inoculum consisted of washed cells (Table 1, expt. 2), growth without added cholesterol was slight. Cultures did grow, however, and in some tubes a slight increase in turbidity was measurable. Further evidence for growth was obtained by serial transfer at 3-day intervals $(0.1 \mathrm{ml} / 10 \mathrm{ml}$ of medium) through four transfers and then a subsequent transfer to medium containing cholesterol.
When a similar medium (medium A), prepared with Trypticase that had been extracted five times with ethyl ether, was inoculated with washed cells, none of the strains grew unless cholesterol was added (Table 1, expt. 3). No growth was detected after four serial transfers in cholesterol-free medium (medium A) and subsequent inoculation into the same medium plus added cholesterol. Growth of strain JR in medium A plus LPS Boivin and cholesterol was less than in a similar medium prepared with Trypticase that had not been extracted with ether. This difference was less pronounced with the other strains. Growth of strains as related to the concentration of cholesterol added to medium $\mathrm{A}$ is shown in Fig. 2.

These experiments show that sterols are required for growth and that sterol or sterolreplacing factors are present in Trypticase. In addition, a positive Liebermann-Burchard reaction was obtained from an ether extract of Trypticase. Robinson (Diss. Abstr. Int. B) reported that two samples of clarified ruminal fluid assayed for cholesterol contained the equivalent of 4.39 and $4.33 \mu \mathrm{mol}$ of cholesterol per $\mathrm{ml}$. Thus, medium containing ruminal fluid should support growth of some sterol-requiring organisms.

Robinson and Hungate (6) reported that they were able to transfer strain JR in a sterol-free, defined medium to which autoclaved $E$. coli cells $(0.5 \mathrm{mg} / \mathrm{ml})$ had been added. This was probably not a sterol-free medium, however,

TABLE 1. Growth of anaerobic mycoplasmas in serum-free media

\begin{tabular}{|c|c|c|c|c|c|}
\hline \multirow{2}{*}{ Medium $^{a}$} & \multicolumn{5}{|c|}{ Growth ${ }^{b}$ of strain: } \\
\hline & JR & $7 \mathrm{LA}$ & $5 \mathrm{LA}$ & $5 \mathrm{LB}$ & $5 \mathrm{LC}$ \\
\hline \multicolumn{6}{|l|}{ Expt 1} \\
\hline MM-10 & $0(72)$ & $0(72)$ & $0(72)$ & $0(72)$ & $0(72)$ \\
\hline MM-10 + LPS $^{c}$ & $0(72)$ & $18(24)$ & $23(24)$ & $37(24)$ & $26(24)$ \\
\hline MM-10 + cholesterol ${ }^{d}$ & $0(72)$ & $0(72)$ & $0(72)$ & $0(72)$ & $0(72)$ \\
\hline MM-10 + LPS + cholesterol & $20(48)$ & $50(48)$ & $37(24)$ & $38(24)$ & $45(28)$ \\
\hline \multicolumn{6}{|l|}{ Expt 2 (washed inoculum) ${ }^{e}$} \\
\hline MM-10 + LPS & $0(72)$ & $3(30)$ & $0(72)$ & $5(24)$ & $0(72)$ \\
\hline MM-10 + LPS + cholesterol & $42(60)$ & $38(20)$ & $58(20)$ & $66(20)$ & $64(20)$ \\
\hline \multicolumn{6}{|l|}{ Exp 3 (washed inoculum) $^{e}$} \\
\hline Medium A + LPS & $0(72)$ & $0(72)$ & $0(72)$ & $0(72)$ & $0(72)$ \\
\hline Medium A + LPS + cholesterol & $8(15)$ & $33(32)$ & $51(12)$ & $53(15)$ & $52(15)$ \\
\hline
\end{tabular}

${ }^{a}$ See Materials and Methods section of reference 5 .

${ }^{\circ}$ Growth of duplicate cultures was measured turbidimeterically in test tubes (18 by $150 \mathrm{~mm}$ ), and the averages are expressed as maximum absorbancy at $600 \mathrm{~nm} \times 100$. Numbers in parentheses are hours of incubation for maximum readings.

'LPS Boivin, $E$. coli $(0.25 \mathrm{mg} / \mathrm{ml}$ of medium).

${ }^{a}$ Cholesterol $(20 \mu \mathrm{g} / \mathrm{ml}$ of medium $)$.

e The inoculum was washed two times with anaerobic mineral solution (5). 


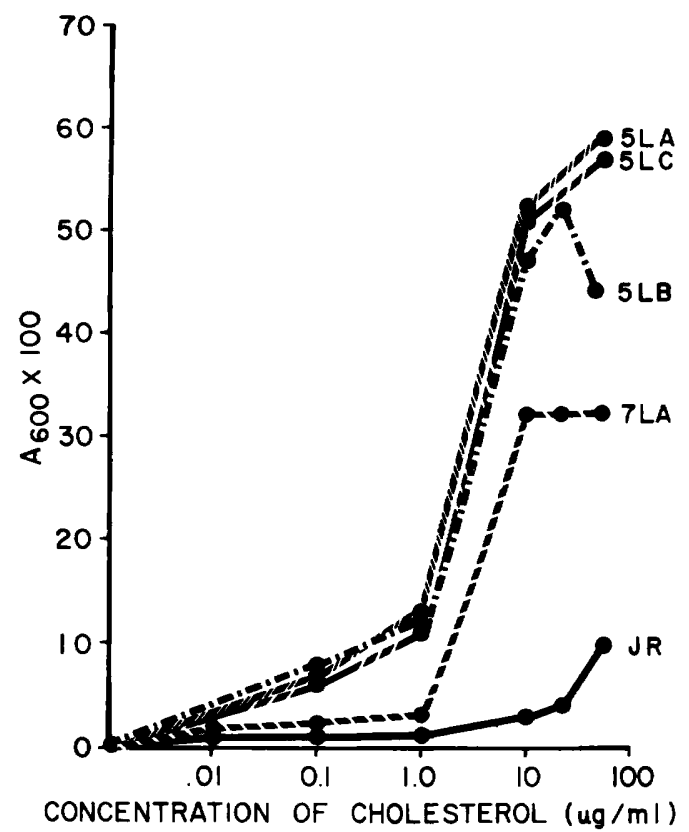

FIG. 2. Growth response of anaerobic mycoplasma strains to cholesterol concentrations in serum-free medium A. Growth of duplicate cultures was measured in 18- $\mathrm{mm}$ diameter test tubes, and the averages were expressed as maximum absorbancy at $600 \mathrm{~nm}$ $\times 100$.

because Schubert et al. (8) reported that $E$. coli cells contain sterols $(4 \mu \mathrm{g} / \mathrm{g}$ of cells). If we assume that the same sterol concentration was in the $E$. coli cells used by Robinson and Hungate, their medium would contain $2 \mathrm{ng}$ of sterol per $\mathrm{ml}$. This is much less than the amount of sterol required for good growth (Fig. 2) but probably enough to permit serial transfers to be made and $E$. coli cells to be lysed.

The selective sensitivity of sterol-requiring mycoplasmas to sodium-polyanethol-sulfonate $(2,3)$, digitonin $(2,4)$, and the polyene antibiotic amphotericin B (8) has been used as an indirect measure to ascertain sterol requirement. Growth of all strains was completely inhibited by the addition of $200 \mu \mathrm{g}$ of digitonin per $\mathrm{ml}$ to a serum-free medium (medium $\mathrm{A}$ ) and partly inhibited by $20 \mu \mathrm{g} / \mathrm{ml}$. Work with other anaerobic mycoplasmas (5) indicated that growth of cholesterol-requiring strains was inhibited by $20 \mu \mathrm{g}$ of digitonin per $\mathrm{ml}$, whereas strains that did not require cholesterol were not inhibited by as much as $200 \mu \mathrm{g} / \mathrm{ml}$ and only slightly inhibited by $500 \mu \mathrm{g} / \mathrm{ml}$. The results of these experiments support the concept that the strains of bacterioclastic mycoplasmas that we studied are dependent on sterols for growth and do not agree with the conclusion of Robinson and Hungate (6) that strain JR does not require cholesterol. Growth was not inhibited by the addition of 5 or $20 \mu \mathrm{g}$ of amphotericin B per ml to medium A. Failure of the drug to inhibit growth of these cholesterol-requiring strains is unexplained. Limited experiments with sodium-polyanethol-sulfonate were inconclusive.

The addition of thallous acetate $(0.2 \%)$ to CRFB medium inhibited growth of the two strains tested (JR and 7LA); this concentration is lower than the minimal inhibitory level reported for a number of other mycoplasmas (10). The addition of $0.6 \mathrm{mg}$ of penicillin per $\mathrm{ml}$ $(1,000 \mathrm{U} / \mathrm{ml})$ did not inhibit growth. Strains JR and 7LA failed to grow in CRFB medium incubated at 26 or $47 \mathrm{C}$ for 1 week but grew well at $37 \mathrm{C}$.

Soluble starch stimulated growth of all of the strains studied. Other carbohydrates had variable effects on growth. The growth of strain 7LA was slightly stimulated by maltose, which had very little affect on strain JR. Glucose was used only by strain 7LA, and galactose was used only by strain JR. Arabinose, fructose, glycerol, lactose, mannose, raffinose, salicin, sucrose, and xylose did not support growth of either strain. Fermentation products from starch by strains JR, 7LA, 5LA, 5LB, and 5LC were similar to those reported from galactose by Robinson and Hungate (6) for strain JR (acetic, formic, lactic, and propionic acids; $\mathrm{CO}_{2}$ and $\mathrm{H}_{2}$ gases; and ethanol).

A suspension of cells of strain 7LA, $6.5 \times 10^{4}$ colony-forming units per $\mathrm{ml}$, was filtered by membrane filters with average pore size designations of 450,220 , and $100 \mu \mathrm{m}$. The filtrates contained $2.1 \times 10^{4},<100$, and $<100$ colony-forming units per $\mathrm{ml}$, respectively. The guanine plus cytosine content of the deoxyribonucleic acid from strain 7LA was $32.5 \mathrm{~mol} \%$ and that of strain JR was $33.7 \mathrm{~mol} \%$, as determined from their buoyant densities in $\mathrm{CsCl}$ gradients relative to a density of $1.710 \mathrm{~g} / \mathrm{cm}^{3}$ for the deoxyribonucleic acid of $E$. coli.

The four bacteriolytic strains described here comprised a single serological group that differs from: Acholesplasma bactoclasticum strain JR; other anaerobic nonbacterioclastic mycoplasmas (5); nonanaerobic mycoplasmas of bovine origin, including $M$. bovingenitalium PG 11 and $M$. agalactiae B 38; $M$. bovirhinis FX 1 ; and Acholesplasma laidlawii PG 10. Details concerning these serologic investigations are to be presented in a separate publication (I. M. Robinson and K. Rhoades, unpublished data).

In consideration of the foregoing, we conclude that the type strain of Acholeplasma bactoclasticum ATCC 27112 (strain JR) (6) and the four 
closely related strains we isolated are dependent on cholesterol for growth and should not be assigned to the family Acholeplasmataceae, genus Acholeplasma. We therefore propose that Acholeplasma bactoclasticum be transferred to Anaeroplasma, a recently proposed genus for anaerobic mycoplasmas (5). This species, Anaeroplasma bactoclasticum (Robinson and Hungate) comb.nov., includes anaerobic mycoplasmas possessing proteolytic and bacteriolytic enzymes.

Emended description of the type strain ATCC 27112. Strain ATCC 27112 ferments starch to produce mainly acetic, formic, and lactic acids, $\mathrm{CO}_{2}, \mathrm{H}_{2}$, and ethanol. The guanine plus cytosine content of the deoxyribonucleic acid is $33.7 \mathrm{~mol} \%$. It does not grow in sterol-free media, but it grows in rumen fluid medium and also in culture medium when rumen fluid is replaced by volatile acids, Trypticase, a vitamin mixture, cholesterol, and the LPS fraction from $E$. coli cells. The growth of this strain is inhibited by thallous acetate $(0.02 \%)$ and digitonin $(200 \mu \mathrm{g} / \mathrm{ml})$.

Properties of Anaeroplasma bactoclasticum. Anaeroplasma bactoclasticum is a strictly anaerobic organism found in the rumen. Cells of young (12- to 18-h-old) cultures are coccoid, about $500 \mathrm{~nm}$ in diameter, gram negative, and nonmotile. A variety of pleomorphic forms are exhibited by older cells. Phase microscopy reveals single cells and dumbbell forms. Clusters of 2 to 10 coccoid forms joined by short filaments are common. The cells are filterable through a $450-\mathrm{nm}$ pore size filter. Electron micrographs of thin sections of cells show cells bounded by a unit membrane with no distinguishable cell wall. This organism does not revert to bacteria with cell walls in the absence of penicillin. Surface colonies average about 1 $\mathrm{mm}$ in diameter, have a dense center and translucent peripheries, and present the socalled "fried-egg" appearance commonly associated with mycoplasma colonies. Subsurface colonies are golden, irregular, and often multilobed.

This organism is insensitive to penicillin but is sensitive to thallous acetate and digitonin. It produces extracellular proteolytic and bacterioclastic enzymes. Starch is fermented, but there is some variation within the species regarding fermentation of other carbohydrates. Fermentation products include: acetic, formic, lactic, and propionic acids, and trace amounts of other volatile fatty acids; $\mathrm{CO}_{2}$ and $\mathrm{H}_{2}$; and ethanol. Cholesterol and a factor in LPS Boivin are required for growth. The optimum temperature is between 30 and $47 \mathrm{C}$. Arginine is not fermented. Chicken embryos are not killed when inoculated with cells of the organism, and no hemolysis of bovine, ovine, or guinea pig blood can be detected in an anaerobic medium. Serologically unrelated to other known mycoplasmas. The guanine plus cytosine content of the deoxyribonucleic acid of the type strain is 33.7 $\mathrm{mol} \%$ and that of a similar strain (7LA) is 32.5 $\mathrm{mol} \%$.

Previous studies (5, 6; Robinson, Diss. Abstr. Int. B), those presented here, and serological investigations suggest that other strains of anaerobic mycoplasmas with a variety of characteristics may inhabit the rumen. The ecological role of these organisms in the rumen is not known.

\section{REPRINT REQUESTS}

Address reprint requests to: Isadore $\mathrm{M}$. Robinson, National Animal Disease Center, P.O. Box 70, Ames, Iowa 50010 .

\section{LITERATURE CITED}

1. Boivin, A., I. Mesrobeanu, and L. Mesrobeanu. 1933. Technique pour la preparation des polysaccharides microbiens specifiques. C. R. Soc. Biol. 113:490-492.

2. Freundt, E. A., B. E. Andrews, H. Erno, M. Kunze, and F. T. Black. 1973. The sensitivity of mycoplasmatales to sodium-polyanethol-sulfonate and digitonin. Zentralbl. Bakteriol. Parasitenkd. Infektionskr. Hyg. Abt. 1: Orig. Reihe A 225:104-112.

3. Kunze, M. 1971. Natrium-polyanethol-sulfonat als diagnostisches Hilfsmittel bei der Differenzierung von Mykoplasemen. Zentralbl. Bakteriol. Parasitenkd. Infektionskr. Hyg. Abt. 1: Orig. 216:501-505.

4. Razin, S., and Z. Shafer. 1969. Incorporation of cholesterol by pleuropneumonia-like organisms. J. Bacteriol. 80:842-850.

5. Robinson, I. M., M. J. Allison, and P. A. Hartman. 1975. Anaeroplasma abactoclasticum gen.nov. and sp.nov.: an obligately anaerobic mycoplasma from the rumen. Int. J. Syst. Bacteriol. 25:173-181.

6. Robinson, J. P., and R. E. Hungate. 1973. Acholeplasma bactoclasticum sp.n., an anaerobic mycoplasma from the bovine rumen. Int. J. Syst. Bacteriol. 23:171-181.

7. Rotten, S. 1972. Differentiation of sterol-requiring from sterol-nonrequiring mycoplasmas by amphotericin B. Appl. Microbiol. 23:659-660.

8. Schubert, K., G. Rose, and C. Hörhold. 1969. Sterol in bacteria, p. 53-56. In K. Schubert (ed.), Symposium über biochemische aspekte der steroidforschung. Akademie-Verlag, Berlin.

9. Subcommittee on the Taxonomy of Mycoplasmatales. 1972. Proposal for minimal standards for descriptions of new species of the order Mycoplasmatales. Int. J. Syst. Bacteriol. 22:184-188.

10. Ward, J. R., S. Madoff, and L. Dienes. 1958. In vitro sensitivity of some bacteria, their L forms and pleuropneumonia-like organisms to antibiotics. Proc. Soc. Exp. Biol. Med. 97:132-135.

11. Westphal, O., O. Luderitz, and F. Bister. 1952. Extraction of bacteria with phenol water. Z. Naturforsch. 7B:148-155. 